\title{
The influence of CYP enzymes and ABCB1 on treatment outcomes in schizophrenia: association of CYP1A2 activity with adverse effects
}

\author{
Marc Cendrós ${ }^{1,2}$, María Jesús Arranz ${ }^{2,3}$, Mercè Torra $^{4}$, Rafael Penadés ${ }^{3,5}$, Alex Gonzalez-Rodriguez ${ }^{6}$, Mercè \\ Brunet $^{4}$, Josefina Perez-Blanco ${ }^{3,7}$, Laura Ibáñez ${ }^{2}$, Alex Serra² ${ }^{2}$ Rosa Catalán ${ }^{3,5}$ \\ 'Eugenomic S.L., Barcelona 08012, Spain. \\ ${ }^{2}$ Fundació Docència i Recerca Mútua Terrassa, Terrassa 08221, Spain. \\ ${ }^{3}$ Centro de Investigación Biomédica en Red de Salud Mental (CIBERSAM), Institut de Recerca Biomèdica Sant Pau (IIB-Sant Pau), \\ Barcelona 08041, Spain. \\ ${ }^{4}$ Pharmacology \& Toxicology Unit, Department Biochemistry \& Molecular Genetics, Hospital Clínic of Barcelona, Barcelona \\ 08036, Spain \\ ${ }^{5}$ Barcelona Clinic Schizophrenia Unit (BCSU), Neurosciences Institute, Hospital Clínic of Barcelona, University of Barcelona, \\ IDIBAPS, Barcelona 08036, Spain. \\ ${ }^{6}$ Department Mental Health, Parc Taulí University Hospital, Sabadell, Barcelona, Sabadell 08208, Spain. \\ ${ }^{7}$ Department Psychiatry, Hospital de la Santa Creu i Sant Pau, Barcelona 08041, Spain.
}

Correspondence to: Dr. María Jesús Arranz, Fundació Docència i Recerca Mútua Terrassa, c \Sant Antoni 19, Terrassa 08221, Spain. E-mail: mjarranz@mutuaterrassa.es; Dr. Rosa Catalán, Barcelona Clinic Schizophrenia Unit (BCSU), Neurosciences Institute, Hospital Clínic of Barcelona, University of Barcelona, IDIBAPS, c/Roselló, 140, Barcelona 08036 Spain.

E-mail: rcatalan@clinic.cat

How to cite this article: Cendrós M, Arranz MJ, Torra M, Penadés R, Gonzalez-Rodriguez A, Brunet M, Perez-Blanco J, Ibáñez L, Serra A, Catalán R. The influence of CYP enzymes and ABCB1 on treatment outcomes in schizophrenia: association of CYP1A2 activity with adverse effects. J Trans/ Genet Genom 2020;4:210-20. http://dx.doi.org/10.20517/jtgg.2020.21

Received: 28 Feb 2020 First Decision: 10 Apr 2020 Revised: 13 May 2020 Accepted: 28 May 2020 Available online: 24 Jun 2020

Science Editor: Tjitske Kleefstra Copy Editor: Xin-Qian Li Production Editor: Jing Yu

\begin{abstract}
Aim: Genetic variants on metabolic and transport enzymes are good candidates to explain inter-individual differences in response to antipsychotics. The aim of this study is to evaluate and compare the influence of the CYP2D6, CYPC19, CYP1A2 and ABCB1 variants on plasma levels, treatment response and side effects of antipsychotics.
\end{abstract}

Methods: Twenty polymorphisms in selected genes were genotyped in 318 patients diagnosed with schizophrenia, schizoaffective or delusional disorder treated with antipsychotics (clozapine, olanzapine, paliperidone, risperidone, aripiprazole and quetiapine). Plasma drug levels were determined after 6 weeks of treatment. The Positive and Negative Symptoms Scale (PANSS) and UKU scale of side effects were recorded at baseline and after 12 weeks

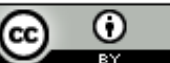

(C) The Author(s) 2020. Open Access This article is licensed under a Creative Commons Attribution 4.0 International License (https://creativecommons.org/licenses/by/4.0/), which permits unrestricted use, sharing, adaptation, distribution and reproduction in any medium or format, for any purpose, even commercially, as long as you give appropriate credit to the original author(s) and the source, provide a link to the Creative Commons license, and indicate if changes were made. 
of treatment. The effect of gene variants on plasma drug levels, treatment response and adverse effects were examined by multinomial regression.

Results: CYP1A2 was found to be associated with psychic side effects $(P=0.02)$, with variants predicting higher enzyme activity associated with lower adverse effects, and was the strongest predictor for this adverse effect of all the studied factors. Functional variants in CYP genes were associated with plasma level differences, with higher activity variants associated with lower plasma levels. No association with improvement of the condition, as measured by the PANSS score, was found in this study.

Conclusion: The results suggest that increased CYPIA2 activity protects against psychic side effects. Few studies have evaluated the impact of genetic factors on treatment response or side effects, and only in relation to a selection of adverse reactions. These results are a step towards better understanding of the factors behind the different aspects of clinical outcomes, such as various adverse effects.

Keywords: Pharmacogenetics, antipsychotics, CYP1A2, CYP2C19, CYP2D6, ABCB1, drug response, adverse drug reactions

\section{INTRODUCTION}

Antipsychotic drugs are the mainstay of treatment for severe mental disorders such as schizophrenia and bipolar disorders. The treatment response to antipsychotic medications has wide inter-individual variability. About 30\%-50\% do not respond adequately and 50\% develop side effects ${ }^{[1]}$. Pharmacokinetics are expected to play an important role in drug response. The effective antipsychotic dose varies among patients, and drug response is highly related to plasma levels, as is drug safety ${ }^{[2]}$. Plasma levels are a direct consequence of the administered dose, but variations on pharmacokinetics, namely drug absorption and metabolism, introduce an element of uncertainty in plasma levels. At the same time, plasma levels and all processes capable of affecting them may modify the dose-dependent fraction of the drug's response. These processes include transport across biological membranes, such as absorption and excretion, and metabolism. Individuals with greater metabolism may require higher doses, while those with lower metabolic rates might be more prone to the drugs' adverse effects and need dose reduction ${ }^{[3-7]}$. With all these variables potential predictors of drug response, which of them, or combination of, is the best predictor of clinical endpoints, if at all.

Genetic variants are known to influence both drug transport and metabolism. Variants in certain genes [i.e., members of the cytochrome (CYP) P450 superfamily, or CYPs] have attracted attention because of their potential to influence treatment response. The CYP superfamily of enzymes is responsible for the metabolism of most drugs used in medical practice, including psychiatric drugs. The activity of the CYP enzymes, as predicted by the allelic variants of the genes encoding for them, can be classified into one of five groups: poor, intermediate, normal, rapid or ultrarapid metabolizers. Most psychiatric drugs are metabolized by the enzymes $C Y P_{2} D_{6}, C Y P_{1} A_{2}$ and $C_{1} P_{2} C_{1}$. Another potentially important gene is $A B C B 1$, which encodes the transport protein MDR1. This protein is expressed in the luminal membrane of enterocytes and it can influence the absorption and bioavailability of substrate drugs. $A B C B 1$ is also expressed in the blood-brain barrier and can affect penetration into the central nervous system $^{[8,9]}$. Although $C Y P$ genetic variants have been widely investigated in relation to mental disorders and their treatment, the contribution of $A B C B 1$ to treatment response and its possible interactions with CYP functional variants is scarcely known. The identification of factors with greater influence on clinical doses and response to psychotropic drugs may have an important effect on the improvement of treatment in psychiatry. CYP enzymes can have genetic variation ranging from loss-of-function alleles to full gene 
duplications, which can have drastic effects on enzymatic activity. The consequences of these variants on the plasma levels of drugs have been extensively reported ${ }^{[3,10-12]}$. The contribution of $A B C B 1$ to plasma levels has been investigated, although there is little evidence that this transporter plays a relevant role ${ }^{[6,12,13]}$. However, there are studies that have reported an association between $A B C B 1$ variants and treatment response, albeit in moderate sample sizes or healthy volunteers ${ }^{[14]}$. The number of studies focusing on pharmacokinetic parameters vastly outnumbers publications evaluating treatment response and side effects. Of these, results on clinical outcomes are unclear. For CYP2D6, there are negative reports ${ }^{[15]}$, although it has also been reported that improvement of the condition is affected by the metabolizing phenotype ${ }^{[7,16]}$. The situation is similar for $A B C B 1$, with some studies having found association ${ }^{[17,18]}$ with antipsychotic responses while others have not ${ }^{[19]}$. There have also been reports of association with genetic variation in CYPs and $A B C B 1$ with adverse effects ${ }^{[20-23]}$. These studies focus on particular adverse effects, such as QT interval prolongation, dyskinesias and prolactinemia. However, no study has evaluated the impact on a wide spectrum of possible adverse effects.

The objective of this study is to evaluate the contribution of genetic variants in CYPs, and $A B C B 1$ genes on antipsychotic drug doses, treatment response and induced side effects, in order to select the factors most predictive of response. To achieve this objective, data regarding efficacy, side-effects, plasma levels and $C Y P s$ and $A B C B 1$ genetic variants were collected in a sample of patients treated with antipsychotics. These patients were participants of a previous study ${ }^{[24]}$ investigating the efficiency of a pharmacogenetic algorithm using the genotype of different CYPs, which concluded that the inclusion of pharmacogenetic information was beneficial for treatment. However, plasma levels were not investigated other than for assessing adherence, and neither was drug transport or in-depth analysis of adverse effects.

\section{METHODS}

\section{Sample}

Three hundred and eighteen patients from a previous work ${ }^{[24]}$ were included in the study. The gender distribution was $55 \%$ male and $45 \%$ female. Mean age was 47 years old. These patients all had a diagnosis of schizophrenia, schizoaffective or delusional disorder. The most commonly used drug was clozapine (135 patients) followed by olanzapine (41 patients), paliperidone (39 patients), risperidone (38 patients), aripiprazole (21 patients), and quetiapine (18 patients); the remaining patients used other drugs. All patients used a single antipsychotic for the duration of the study. One hundred and thirty of these patients received a pharmacogenetic intervention consisting of adjustment of their antipsychotic drug dose according to their CYP genetic profile when required, while the rest received standard treatment. This cohort is described in Table 1.

\section{Biochemical parameters}

The plasma concentrations of both the antipsychotic and its main metabolite were determined at 6 weeks after starting treatment, when steady state was achieved. Since treatment doses were not modified after reaching steady state, plasma levels were assumed to be stable for the remainder of the treatment. The plasma concentration of parent antipsychotic drugs, metabolites and active moiety were measured by a validated high-performance liquid chromatography (HPLC) method, using ultraviolet visible diode array detection and solid-phase extraction on cyano cartridges. Compounds were separated on a C8 reversedphase column with a gradient of acetonitrile and phosphate buffer $50 \mathrm{mM}, \mathrm{pH} 3.8$ and detected at 210 and $278 \mathrm{~nm}$. To assure high precision and accuracy of the method, an internal standard was included in the sample preparation and quantitative evaluation. The within- and between day precision expressed as coefficient of variation $(\mathrm{CV}) \%$ were $<10 \%$. The quality of analyses was subject to a program of internal quality control and external quality assessment ${ }^{[25]}$. 
Table 1. General information about the study sample

\begin{tabular}{lll}
\hline Age & Mean (years) & SD (\%) \\
\hline Gender & 43.9 & $13.8 \%$ \\
Men & 175 & Percent \\
Women & 143 & $55 \%$ \\
Diagnosis & & $45 \%$ \\
Schizophrenia & 243 & Percent \\
Major depression & 3 & $76.4 \%$ \\
Brief psychosis & 1 & $0.9 \%$ \\
Delusional disorder & 55 & $0.4 \%$ \\
Schizoaffective disorder & 16 & $17.3 \%$ \\
Treatment & & $5 \%$ \\
Clozapine & 141 & Percent \\
Olanzapine & 43 & $44.3 \%$ \\
Paliperidone & 41 & $13.5 \%$ \\
Risperidone & 40 & $12.9 \%$ \\
Aripiprazole & 22 & $12.6 \%$ \\
Quetiapine & 19 & $6.9 \%$ \\
Ziprasidone & 3 & $5.9 \%$ \\
Haloperidol & 2 & $0.9 \%$ \\
Asenapine & 2 & $0.6 \%$ \\
Levomepromazine & 2 & $0.6 \%$ \\
Trifluoperazine & 2 & $0.6 \%$ \\
Perfenazine & 1 & $0.6 \%$ \\
Pimozide & 1 & $0.3 \%$ \\
Altered PGX & & $0.3 \%$ \\
Yes & 243 & Percent \\
No & 75 & $76.4 \%$ \\
\hline & & $23.6 \%$ \\
\hline
\end{tabular}

SD: standard deviation; Altered PGX: patients with a non-NM metabolism for the prescribed drug

The dose used for each patient was recorded and standardized into olanzapine-equivalent doses between the different antipsychotic agents ${ }^{[26]}$ ).

\section{Clinical parameters}

Clinical progression of patients was evaluated with the Positive and Negative Symptoms Scale (PANSS) ${ }^{[27]}$. Patients were evaluated at the beginning of the study and 12 weeks after treatment. Similarly, the development of adverse events was tracked with the UKU side effects rating scale ${ }^{[28]}$ at baseline and again at 12 weeks after starting treatment. The UKU scores for different side effects were grouped into four categories: psychic, neurologic, autonomic and others. A fifth and final category, total UKU, captures the overall emergence of any side effect, as it combines the scores of all UKU categories.

\section{Genetic profile}

Whole blood samples were taken from patients at the beginning of the study. DNA was extracted with a commercial kit (QIAmp DNA mini Kit, Qiagen) following the manufacturers recommendations. Genotyping of twenty functional polymorphisms in the $A B C B 1, C Y P_{2} C_{1}$, $C Y P_{1} A_{2}$ and $C Y P_{2} D_{6}$ genes, including copy number variations on the $C Y P_{2} D 6$ gene, was performed using iPlex ${ }^{\circ}$ Gold chemistry and the MassARRAY platform (CEGEN-PRB2-ISCIII, University of Santiago de Compostela, Spain). Table 2 summarizes the polymorphisms investigated and their predicted phenotype. The selected polymorphisms in cytochromes led to altered enzymatic activity, ranging from gene duplication related to increased protein production to loss of functionial alleles. The polymorphism in $A B C B 1(3435 \mathrm{C}>\mathrm{T})$ leads to a synonymous substitution, however this change has been associated with lower expression, possibly due to linkage with a different causal polymorphism or by ribosome stalling, i.e., a less efficient translation by using a less usual 
Table 2. Activity score for the studied polymorphisms

\begin{tabular}{|c|c|c|c|}
\hline Gene & Allele designation & Allele activity score & rsID \\
\hline CYP1A2 & ${ }^{\star} 1 \mathrm{~F}$ & 1.5 & rs762551 \\
\hline \multirow[t]{2}{*}{ CYP2C19 } & $\star 2$ & 0 & rs12769205 \\
\hline & *17 & 1.5 & rs12248560 \\
\hline \multirow[t]{16}{*}{ CYP2D6 } & $\star 3$ & 0 & rs35742686 \\
\hline & *4 & 0 & rs3892097 \\
\hline & *5 & 0 & gene deletion \\
\hline & *6 & 0 & rs5030655 \\
\hline & $\star 7$ & 0 & rs5030867 \\
\hline & $\star 8$ & 0 & rs5030865 \\
\hline & *9 & 0.5 & rs5030656 \\
\hline & ${ }^{*} 10$ & 0.25 & rs1065852 \\
\hline & *11 & 0 & rs201377835 \\
\hline & *17 & 0.5 & rs28371706 \\
\hline & *19 & 0 & rs72549353 \\
\hline & $\star 20$ & 0 & rs72549354 \\
\hline & *29 & 0.5 & rs61736512 \\
\hline & *31 & 0 & rs267608319 \\
\hline & $\star 41$ & 0.5 & rs28371725 \\
\hline & $x N$ & 2 & gene duplication \\
\hline$A B C B 1$ & $3435 C>T$ & Reduced expression & rs1045642 \\
\hline
\end{tabular}

Activity score: 0-loss of function, 0.25-drastically reduced function, 0.5-reduced function, 1-normal function, 1.5-increased function, 2-gene duplication, rsID: accession number on the dbSNP database

$\operatorname{codon}^{[29]}$. For CYPs, genotype information was converted into activity scores, according to Gaedigk et al. ${ }^{[30]}$ and adapted to genes other than CYP2D6 using the same criteria. Phenotype imputation based on genotype was done according to the latest consensus article published by the Clinical Pharmacogenetics Implementation Consortium (CPIC), with the activity score for CYP2D $6^{*} 10$ updated to the 2019 revision ${ }^{[31,32]}$. The total activity score for an individual is the result of adding the scores of the two alleles they carry for that gene.

After obtaining their genetic profile, 73 of the subjects were found to be carriers of genetic combinations that would modify their ability to metabolize the drug they were prescribed. This is represented by ultrarapid (UM) for CYP1A2 in patients on clozapine or olanzapine, UM or poor metabolizer (PM) for $\mathrm{CYP}_{2} \mathrm{C}_{1} 9$ in clozapine users, and PMs, intermediate metabolizer (IMs) or UMs for CYP2D6 in patients on risperidone, aripiprazole, haloperidol, pimozide or trifluoperazine.

\section{Statistical analysis}

Multivariate regression analyses of the results were performed using SPSS Statistics v23.0.0.0 (IBM). Plasma levels, change in PANSS and in UKU scores were used as dependent variables, with genetic information on the different $C Y P_{s}\left(C Y P_{1} A 2, C Y P_{2} C_{19}\right.$ and $\left.C Y P_{2} D_{6}\right)$ and $A B C B 1$ being the explanatory variables. Gender, age, dose, type of antipsychotic and pharmacogenetic intervention were also included as covariates.

\section{RESULTS}

The influence of genetic factors on plasma levels was investigated using the different $C Y P s$ and $A B C B 1$ as predictors, and age, gender, dose, and the intervention arm as covariables. The full sample of 318 patients was used in all cases, but to account for the different affinities of the antipsychotics for each protein, the interaction between the antipsychotic and $C Y P_{1} A 2, C Y P_{2} C_{19}, C Y P_{2} D_{6}$ and $A B C B 1$ genes was used as a predictor. These interactions showed significant association with plasma levels with $P$-values $<0.001$ in all cases [Table 3]. The interaction with $A B C B 1$ had roughly the same $P$-value as $C Y P_{1} A 2$ and $C Y P_{2} C 19$, while 
Table 3. Association of genetic factors with levels, response and side effects

\begin{tabular}{|c|c|c|c|c|c|c|c|}
\hline & LEVELS & PANSS & T UKU & P UKU & N UKU & A UKU & O UKU \\
\hline \multicolumn{8}{|l|}{ CYP1A2 } \\
\hline Model $P$-value & $5.05 \times 10^{-8}$ & 0.39 & 0.03 & 0.01 & 0.19 & 0.72 & 0.08 \\
\hline Age & 0.30 & 0.12 & 0.22 & 0.03 & 0.32 & 0.94 & 0.23 \\
\hline Gender & 0.20 & 0.21 & 0.59 & 0.92 & 0.73 & 0.97 & 0.39 \\
\hline Dose & 0.30 & 0.31 & 0.01 & 0.31 & 0.03 & 0.90 & 0.01 \\
\hline Intervention & 0.63 & 0.96 & 0.37 & 0.08 & 0.85 & 0.82 & 0.94 \\
\hline Antipsychotic ${ }^{\star} C Y P 1 A 2$ & $1.26 \times 10^{-9}$ & 0.40 & 0.06 & 0.01 & 0.58 & 0.10 & 0.75 \\
\hline \multicolumn{8}{|l|}{ CYP2C19 } \\
\hline Model $P$-value & $3.16 \times 10^{-8}$ & 0.43 & 0.11 & 0.22 & 0.09 & 0.86 & 0.09 \\
\hline Age & 0.45 & 0.07 & 0.27 & 0.03 & 0.25 & 0.84 & 0.25 \\
\hline Gender & 0.13 & 0.22 & 0.43 & 0.81 & 0.68 & 0.90 & 0.39 \\
\hline Dose & 0.18 & 0.36 & 0.01 & 0.34 & 0.02 & 0.91 & 0.01 \\
\hline Intervention & 0.33 & 0.86 & 0.63 & 0.30 & 0.89 & 0.63 & 1 \\
\hline Antipsychotic ${ }^{\star}$ CYP2C19 & $1 \times 10^{-9}$ & 0.83 & 1 & 0.57 & 0.29 & 0.22 & 0.79 \\
\hline \multicolumn{8}{|l|}{ CYP2D6 } \\
\hline Model $P$-value & $3.46 \times 10^{-8}$ & 0.5 & 0.08 & 0.07 & 0.13 & 0.75 & 0.09 \\
\hline Age & 0.38 & 0.17 & 0.19 & 0.03 & 0.28 & 0.97 & 0.23 \\
\hline Gender & 0.18 & 0.26 & 0.61 & 0.95 & 0.69 & 0.97 & 0.41 \\
\hline Dose & 0.24 & 0.3 & 0.01 & 0.31 & 0.03 & 0.85 & 0.01 \\
\hline Intervention & 0.56 & 0.90 & 0.42 & 0.1 & 0.91 & 0.74 & 0.87 \\
\hline Antipsychotic ${ }^{\star}$ CYP2D6 & $5.97 \times 10^{-10}$ & 0.49 & 0.29 & 0.12 & 0.25 & 0.11 & 0.99 \\
\hline \multicolumn{8}{|l|}{$A B C B 1$} \\
\hline Model $P$-value & $3.81 \times 10^{-8}$ & 0.44 & 0.66 & 0.17 & 0.12 & 0.84 & 0.07 \\
\hline Age & 0.30 & 0.06 & 0.20 & 0.03 & 0.33 & 0.85 & 0.19 \\
\hline Gender & 0.20 & 0.33 & 0.62 & 0.90 & 0.84 & 1 & 0.56 \\
\hline Dose & 0.30 & 0.50 & 0.01 & 0.27 & 0.02 & 0.77 & 0.004 \\
\hline Intervention & 0.63 & 0.91 & 0.59 & 0.35 & 0.97 & 0.67 & 0.94 \\
\hline Antipsychotic ${ }^{\star} A B C B 1$ & $1.26 \times 10^{-9}$ & 0.63 & 0.25 & 0.19 & 0.55 & 0.19 & 0.41 \\
\hline \multicolumn{8}{|l|}{ Affected by CYP } \\
\hline Model $P$-value & $3.46 \times 10^{-8}$ & 0.22 & 0.09 & 0.09 & 0.05 & 0.66 & 0.12 \\
\hline Age & 0.97 & 0.09 & 0.25 & 0.02 & 0.11 & 0.80 & 0.16 \\
\hline Gender & 0.33 & 0.1 & 0.27 & 0.71 & 0.43 & 0.88 & 0.28 \\
\hline Dose & 0.22 & 0.06 & 0.01 & 0.34 & 0.02 & 0.79 & 0.01 \\
\hline Intervention & 0.79 & 0.89 & 0.52 & 0.21 & 1 & 0.55 & 0.96 \\
\hline Antipsychotic & $6.75 \times 10^{-11}$ & 0.73 & 0.44 & 0.08 & 0.11 & 0.08 & 0.96 \\
\hline CYPS & 0.37 & 0.59 & 0.38 & 0.41 & 0.62 & 0.84 & 0.51 \\
\hline
\end{tabular}

$P$-values for Levels: plasma levels, PANSS: change in PANSS score; T UKU: change in total UKUs, P UKU: change in psychic UKUs; N UKU: change in neurologic UKUs, A UKU: change in autonomic UKUs; O UKU: change in other UKUs

being one order of magnitude higher than CYP2D6 ( $P$-values of $1.26 \times 10^{-9}, 1.26 \times 10^{-9}, 1 \times 10^{-9}$ and $5.97 \times 10^{-10}$ for $A B C B 1, C Y P_{1} A 2, C Y P_{2} C_{1} 19$ and $C Y P_{2} D_{6}$, respectively).

Regarding change in PANSS scores, none of the studied genetic variants showed a statistically significant association, and the models used were not statistically significant either. Regarding the change in UKU scores, CYP1A2 models were statistically significant for total UKUs $(P=0.03)$ and psychic UKUs $(P=$ $0.014)$. Of these models, antipsychotic ${ }^{\star} \mathrm{CYP} 1 \mathrm{~A} 2$ resulted in a significant association with psychic UKU only $(P=0.007)$, with higher activity scores being associated with less adverse effects. The mean differences in psychic UKU at baseline minus UKU at 12 weeks was 0.67 for Activity Score $(A S)=1$ (Normal Metabolizers), 2.12 for AS = 1.5 (Rapid Metabolizers) and 2.13 for AS $=2$ (Ultrarrapid Metabolizers). This association was further explored by comparing the psychic UKU using only the portion of the sample treated with the CYP1A2 substrates clozapine and olanzapine, therefore removing the confounding effect of other substrates. This association did not change when the antipsychotic class was reduced to the substrates 
(clozapine and olanzapine) and non-substrates of CYP1A2. Although antipsychotico* $\mathrm{CYP}_{1} \mathrm{~A} 2$ bordered on the significance threshold for total UKU, it was statistically not significant $(P=0.06)$.

The combined effect of all CYPs was explored using a dichotomic variable representing whether each patient had an altered metabolism for the drug they were taking or not. In these tests, the antipsychotic was added as a covariable. However, altered metabolism was not found to be associated with plasma levels, change in PANSS or change in any of the UKU scores, although the model itself was marginally significant in relation to neurologic UKUs $(P=0.05)$.

\section{DISCUSSION}

The aim of this study was to investigate the effects of genetic variants in pharmacokinetic genes on clinical endpoints to compare their influence on the outcome of treatment. The effect of metabolism on adverse effects was observed for CYP1A2 on psychological UKUs, but not for other clinical endpoints. No correlation between any of the investigated genetic factors with PANSS was found.

The association between $C Y P_{1} A_{2}, C Y P_{2} C_{19}, C Y P_{2} D 6$ and $A B C B 1$ and plasma levels, despite the very low $P$-values, may have explanations other than genetic variation. Unlike clinical dose data, which was transformed to olanzapine equivalents, plasma levels did not receive any standardizing transformation, and since different molecules reach different concentrations in blood, even in normal circumstances, the type of antipsychotic that can reach significance by itself, with $P$-values even lower than those observed for any of the antipsychotic-gene interactions, is observed at the end of Table 3. Therefore, the association observed with the interaction is most likely driven by the antipsychotic component of the interaction, which would be expected to be significant even without a real influence of the genotype. This does not rule out a true contribution of metabolism or transport on plasma levels. In fact, there have been numerous reports on the association of $C_{1} P_{2} D 6$ with plasma levels of risperidone, aripiprazole, haloperidole, zuclopenthixole, and pimozide $^{[3,6,10,11,13,33,34]}$ and CYP1A2 with olanzapine ${ }^{[35]}$, which is consistent with their metabolic pathways. For clozapine, the existing data shows a clear association with $C Y P_{1} A_{2}$ activity, including the inducer effect of smoking on plasma levels but the effect of genetic variation itself has failed to show an association in some studies ${ }^{[36-38]}$. There are also reports on the association of $A C B C 1$ with plasma levels of aripiprazole and quetiapine ${ }^{[39,40]}$. It should be noted that $C Y P 2 D 6$ had the strongest association, at one order of magnitude lower than the other three genes, which could reflect a higher influence.

Regarding changes in PANSS scores, none of the CYPs or ABCB1 genetic variants investigated showed any effect. In fact, no predictors of clinical efficacy were found at all in this study. CYPs are expected to be related more to side effects than efficacy, because most genetic variations lead to decreased metabolism, whereas the lack of efficacy is expected to be observed when metabolism is increased. Studies that have addressed the effect of metabolism on efficacy have had contradictory results. A large study by Jukic et al. ${ }^{[3]}$ found that both very high and very low $\mathrm{CYP}_{2} \mathrm{D}_{6}$ metabolism (PMs or UMs) are predictors for treatment switch from risperidone. It should be noted that treatment switching could be due to the lack of efficacy but also, from intolerable adverse effects. van de Bilt et al. ${ }^{[15]}$ investigated the possibility that ultrarapid metabolism might lead to the lack of improvement, but could not confirm this hypothesis. Regarding CYP1A2, the studied polymorphism leads to increased expression, and thus it is reasonable to think that carriers would have a lower change in PANSS due to increased metabolism. This was observed by Czerwensky et al. ${ }^{[35]}$ reporting an inverse correlation between predicted CYP1A2 activity and improvement of symptoms in patients treated with clozapine and olanzapine. Nonetheless, increased metabolism has also been described as a factor for good response. Piatkov et al ${ }^{[41]}$ observed in their clozapine-treated cohort that increased metabolism through $C_{2} P_{2} C_{1} 9$ leads to a lower risk of diabetes and a higher chance of clinical improvement. $A B C B 1$ has also been studied regarding efficacy. Papazisis et al. ${ }^{[17]}$ found an 
involvement of $A B C B 1$ in the evolution of PANSS, but only in patients with decreased CYP2D6 activity, and also only for the rs2032582 (2677G $>\mathrm{T} / \mathrm{A})$ polymorphism in $A B C B 1$, but not rs1045642 (3435C > T), which is the one used in the present study. Other authors, however, have been able to find an effect of $3435 \mathrm{C}>\mathrm{T}$ on clinical improvement ${ }^{[1,40]}$. The effect of $A B C B 13435 \mathrm{C}>\mathrm{T}$ might be limited to specific substrates or apply only to haplotypes.

It was found that $C Y P_{1} A_{2}$ genetic variants were directly associated with changes in psychological UKU. As expected, higher CYP1A2 activity is related to less psychological adverse effects due to the dose-dependent nature of most adverse drug reactions. The association of CYP1A2 variants with psychological UKUs was stronger than that of age, highlighting its importance. While drug dose was associated with UKUs in most cases, this was not true for psychological adverse effects, which suggests that metabolic activity is more important than the actual dose regarding this class of adverse reactions. Local metabolism in the brain, as opposed to liver metabolism, could lead to changes in local exposure not reflected by plasma levels. CYP1A2 is expressed in the rat brain, and has also been reported to be expressed in human brains ${ }^{[42,43]}$. As clozapine, a CYP1A2 substrate, is the drug that was used in more patients than any of the other agents, this study was better powered to detect differences regarding CYP1A2. It is possible that the lack of significant results for other genes is due to the lower relative abundance of substrates for the corresponding pathways. It is also expected that dose is related to overall side effects, but this association was not seen for autonomic or psychic UKUs. This makes the effect of $C Y P_{1} A 2$ on the latter particularly interesting, because it revealed a marker for adverse effects that cannot be predicted with dose. Knowing which side effects are most likely to happen can help physicians with follow-up of their patients, so that they can focus on psychic adverse effects in those patients with lower CYP1A2 activity scores.

There are some limitations in this study that might have hampered the discovery of other associations. While the sample size of the whole study was moderate, it was not possible to divide into groups based on medications, as these groups would have been too small. Furthermore, it would have been interesting to check the possibility of drug-drug interactions, as some medications are known to be inhibitors or inducers or $C Y P$ s and/or $A B C B 1$, so a patient can have an actual phenotype that differs from what one would predict based on genotype. However, most patients were on antipsychotic monotherapy and concomitant treatment should not have significantly affected the results. Other factors such as smoking habits and diet could not be considered due to the lack of specific information. Further studies should address these possible confounding factors.

In conclusion, there is a possible association between CYP1A2 and psychic adverse effects, which is concordant with the known properties of clozapine. This association should be considered preliminary until it is confirmed in an independent study. None of the other studied genes showed any effect on treatment, as measured by changes in PANSS and UKU scores. These results suggest that patients with higher CYP1A2 activity would be less likely to experience psychic adverse effects.

\section{DECLARATIONS}

\section{Acknowledgments}

We are extremely grateful to all participants. We thank the Spanish Ministry of Economy, Industry, and the European Funds for Regional Development (Fondo Europeo de Desarrollo Regional, FEDER) for their support. We are indebted to the IDIBAPS Biobank, integrated in the Spanish National Biobank Network, for samples and data procurement.

\section{Authors' contributions}

Study design: Cendrós M, Arranz MJ, Catalán R

Conducted pharmacogenetic studies: Cendrós M, Ibáñez L, Serra A, Arranz MJ 
Conducted pharmacokinetic studies: Brunet $\mathrm{M}$, Torra $\mathrm{M}$

Performed analysis of results: Cendrós M, Arranz MJ, Catalán R

All authors contributed to the interpretation and discussion of results.

\section{Availability of data and materials}

Not applicable.

\section{Financial support and sponsorship}

This study was financed by Institute Carlos III (FIS PI11/02006 and FIS PI16/01029) and grant PT13/001, ISCIII-SGEFI/FEDER

\section{Conflicts of interest}

All authors declared that there are no conflicts of interest.

\section{Ethical approval and consent to participate}

The research was performed in accordance with the Declaration of Helsinki and all participants gave written informed consent. AEMPS code: RCC-ANT-2013-01

\section{Consent for publication}

Not applicable.

\section{Copyright}

(c) The Author(s) 2020.

\section{REFERENCES}

1. Iversen TSJ, Steen NE, Dieset I, Hope S, Mørch R, et al. Side effect burden of antipsychotic drugs in real life-Impact of gender and polypharmacy. Prog Neuropsychopharmacol Biol Psychiatry 2018;82:263-71.

2. McCutcheon R, Beck K, D’Ambrosio E, Donocik J, Gobjila C, et al. Antipsychotic plasma levels in the assessment of poor treatment response in schizophrenia. Acta Psychiatr Scand 2018;137:39-46.

3. Jukic MM, Smith RL, Haslemo T, Molden E, Ingelman-Sundberg M. Effect of CYP2D6 genotype on exposure and efficacy of risperidone and aripiprazole: a retrospective, cohort study. Lancet Psychiatry 2019;6:418-26.

4. Ruan CJ, Zang YN, Wang CY, Cheng YH, Sun C, et al. Clozapine metabolism in east Asians and caucasians: a pilot exploration of the prevalence of poor metabolizers and a systematic review. J Clin Psychopharmacol 2019;39:135-44.

5. Kurylev AA, Brodyansky VM, Andreev BV, Kibitov AO, Limankin OV, et al. The combined effect of CYP2D6 and DRD2 Taq1A polymorphisms on the antipsychotics daily doses and hospital stay duration in schizophrenia inpatients (observational naturalistic study). Psychiatr Danub 2018;30:157-63.

6. Mas S, Gassò P, Alvarez S, Parellada E, Bernardo M, et al. Intuitive pharmacogenetics: spontaneous risperidone dosage is related to CYP2D6, CYP3A5 and ABCB1 genotypes. Pharmacogenomics J 2012;12:255-9.

7. Kirchheiner J, Gründemann D, Schömig E. Contribution of allelic variations in transporters to the phenotype of drug response. J Psychopharmacol 2006;20:27-32.

8. Fromm MF. Importance of P-glycoprotein at blood-tissue barriers. Trends Pharmacol Sci 2004;25:423-9.

9. Bruckmueller H, Martin P, Kähler M, Haenisch S, Ostrowski M, et al. Clinically relevant multidrug transporters are regulated by microRNAs along the human intestine. Mol Pharm 2017;14:2245-53.

10. van der Weide K, van der Weide J. The influence of the CYP3A4*22 polymorphism and CYP2D6 polymorphisms on serum concentrations of aripiprazole, haloperidol, pimozide, and risperidone in psychiatric patients. J Clin Psychopharmacol 2015;35:228-36.

11. Filipce A, Naumovska Z, Nestorovska AK, Sterjev Z, Brezovska K, et al. Evaluation of correlation between the pharmacogenetic profiles of risperidone treated psychiatry patients with plasma and urine concentration of risperidone and its active moiety 9-OH rsperidone determined with optimized bioanalytical LC method. Pril (Makedon Akad Nauk Umet Odd Med Nauki) 2018;39:97-106.

12. Bakken GV, Molden E, Hermann M. Impact of genetic variability in CYP2D6, CYP3A5, and ABCB1 on serum concentrations of quetiapine and N-desalkylquetiapine in psychiatric patients. Ther Drug Monit 2015;37:256-61.

13. Suzuki T, Mihara K, Nakamura A, Kagawa S, Nagai G, et al. Effects of genetic polymorphisms of CYP2D6, CYP3A5, and ABCB1 on the steady-state plasma concentrations of aripiprazole and its active metabolite, dehydroaripiprazole, in Japanese patients with schizophrenia. Ther Drug Monit 2014;36:651-5.

14. González-Vacarezza N, Dorado P, Peñas-Lledó EM, Fariñas H, Estévez-Carrizo FE, et al. MDR-1 genotypes and quetiapine 
pharmacokinetics in healthy volunteers. Drug Metabol Drug Interact 2013;28:163-6.

15. van de Bilt MT, Prado CM, Ojopi EP, Sousa RT, Loch AA, et al. Cytochrome P450 genotypes are not associated with refractoriness to antipsychotic treatment. Schizophr Res 2015;168:587-8.

16. Almoguera B, Riveiro-Alvarez R, Lopez-Castroman J, Dorado P, Vaquero-Lorenzo C, et al; Spanish Consortium of Pharmacogenetics Research in Schizophrenia. CYP2D6 poor metabolizer status might be associated with better response to risperidone treatment. Pharmacogenet Genomics 2013;23:627-30.

17. Papazisis G, Goulas A, Sarrigiannidis A, Bargiota S, Antoniadis D, et al. ABCB1 and CYP2D6 polymorphisms and treatment response of psychotic patients in a naturalistic setting. Hum Psychopharmacol 2018;33.

18. Vijayan NN, Mathew A, Balan S, Natarajan C, Nair CM, et al. Antipsychotic drug dosage and therapeutic response in schizophrenia is influenced by ABCB1 genotypes: a study from a south Indian perspective. Pharmacogenomics 2012;13:1119-27.

19. Kastelic M, Koprivsek J, Plesnicar BK, Serretti A, Mandelli L, et al. MDR1 gene polymorphisms and response to acute risperidone treatment. Prog Neuropsychopharmacol Biol Psychiatry 2010;34:387-92.

20. Suzuki Y, Tsuneyama N, Fukui N, Sugai T, Watanabe J, et al. Effect of risperidone metabolism and P-glycoprotein gene polymorphism on QT interval in patients with schizophrenia. Pharmacogenomics J 2014;14:452-6.

21. Grădinaru R, Andreescu N, Nussbaum L, Suciu L, Puiu M. Impact of the CYP2D6 phenotype on hyperprolactinemia development as an adverse event of treatment with atypical antipsychotic agents in pediatric patients. Ir J Med Sci 2019;188:1417-22.

22. Ivanova SA, Filipenko ML, Vyalova NM, Voronina EN, Pozhidaev IV, et al. CYP1A2 and CYP2D6 gene polymorphisms in schizophrenic patients with neuroleptic drug-induced side effects. Bull Exp Biol Med 2016;160:687-90.

23. Hattori S, Suda A, Kishida I, Miyauchi M, Shiraishi Y, et al. Effects of ABCB1 gene polymorphisms on autonomic nervous system activity during atypical antipsychotic treatment in schizophrenia. BMC Psychiatry 2018;18:231.

24. Arranz MJ, Gonzalez-Rodriguez A, Perez-Blanco J, Penadés R, Gutierrez B, et al. A pharmacogenetic intervention for the improvement of the safety profile of antipsychotic treatments. Transl Psychiatry 2019;9:177.

25. Frahnert C, Rao ML, Grasmäder K. Analysis of eighteen antidepressants, four atypical antipsychotics and active metabolites in serum by liquid chromatography: a simple tool for therapeutic drug monitoring. J Chromatogr B 2003;794:35-47.

26. Leucht S, Samara M, Heres S, Patel MX, Furukawa T, et al. Dose equivalents for second-generation antipsychotic drugs: the classical mean dose method. Schizophr Bull 2015;41:1397-402.

27. Kay SR, Fiszbein A, Opler LA. The positive and negative syndrome scale (PANSS) for schizophrenia. Schizophrenia Bull 1987;13:261-76.

28. Kimchi-Sarfaty C, Oh JM, Kim IW, Sauna ZE, Calcagno AM, et al. A “silent” polymorphism in the MDR1 gene changes substrate specificity. Science 2007;318:1382-3.

29. Lingjaerde O, Ahlfors UG, Bech P, Dencker SJ, Elgen K. The UKU side effect rating scale. A new comprehensive rating scale for psychotropic drugs and a cross-sectional study of side effects in neuroleptic-treated patients. Acta Psychiatr Scand Suppl 1987;334:1-100.

30. Gaedigk A, Simon SD, Pearce RE, Bradford LD, Kennedy MJ, et al. The CYP2D6 activity score: translating genotype information into a qualitative measure of phenotype. Clin Pharmacol Ther 2008;83:234-42.

31. Caudle KE, Dunnenberger HM, Freimuth RR, Peterson JF, Burlison JD, et al. Standardizing terms for clinical pharmacogenetic test results: consensus terms from the clinical pharmacogenetics implementation consortium (CPIC). Genet Med 2017;19:215-223.

32. Caudle KE, Sangkuhl K, Whirl-Carrillo M, Swen JJ, Haidar CE, et al. Standardizing CYP2D6 genotype to phenotype translation: consensus recommendations from the clinical pharmacogenetics implementation consortium and dutch pharmacogenetics working group. Clin Transl Sci 2020;13:116-24.

33. Jovanović N, Božina N, Lovrić M, Medved V, Jakovljević M, et al. The role of CYP2D6 and ABCB1 pharmacogenetics in drug-naïve patients with first-episode schizophrenia treated with risperidone. Eur J Clin Pharmacol 2010;66:1109-17.

34. Lisbeth P, Vincent H, Kristof M, Bernard S, Manuel M, et al. Genotype and co-medication dependent CYP2D6 metabolic activity: effects on serum concentrations of aripiprazole, haloperidol, risperidone, paliperidone and zuclopenthixol. Eur J Clin Pharmacol 2016;72:175-84.

35. Czerwensky F, Leucht S, Steimer W. CYP1A2*1D and *1F polymorphisms have a significant impact on olanzapine serum concentrations. Ther Drug Monit 2015;37:152-60.

36. Jaquenoud Sirot E, Knezevic B, Morena GP, Harenberg S, Oneda B, et al. ABCB1 and cytochrome P450 polymorphisms: clinical pharmacogenetics of clozapine. J Clin Psychopharmacol 2009;29:319-26.

37. Tóth K, Csukly G, Sirok D, Belic A, Kiss Á, et al. Potential role of patients' CYP3A-status in clozapine pharmacokinetics. Int J Neuropsychopharmacol 2017;20:529-37.

38. Huang HC, Lua AC, Wu LS, Wu BJ, Lee SM, et al. Cigarette smoking has a differential effect on the plasma level of clozapine in Taiwanese schizophrenic patients associated with the CYP1A2 gene-163A/C single nucleotide polymorphism. Psychiatr Genet 2016;26:172-7.

39. Rafaniello C, Sessa M, Bernardi FF, Pozzi M, Cheli S, et al. The predictive value of ABCB1, ABCG2, CYP3A4/5 and CYP2D6 polymorphisms for risperidone and aripiprazole plasma concentrations and the occurrence of adverse drug reactions. Pharmacogenomics J 2018;18:422-30.

40. Nikisch G, Baumann P, Oneda B, Kiessling B, Weisser H, et al. Cytochrome P450 and ABCB1 genetics: association with quetiapine and norquetiapine plasma and cerebrospinal fluid concentrations and with clinical response in patients suffering from schizophrenia. A pilot study. J Psychopharmacol 2011;25:896-907.

41. Piatkov I, Caetano D, Assur Y, Lau SL, Coelho M, ET AL. CYP2C19*17 protects against metabolic complications of clozapine treatment. World J Biol Psychiatry 2017;18:521-7.

42. Voirol P, Jonzier-Perey M, Porchet F, Reymond MJ, Janzer RC, et al. Cytochrome P-450 activities in human and rat brain microsomes. 
Brain Res 2000;855:235-43.

43. Agúndez JA, Gallardo L, Martínez C, Gervasini G, Benítez J. Modulation of CYP1A2 enzyme activity by indoleamines: inhibition by serotonin and tryptamine. Pharmacogenetics 1998;8:251-8. 